\title{
The Inventory of Callous-Unemotional Traits: Psychometric properties among referred and non-referred Portuguese female juveniles
}

\author{
Pedro Pechorro $^{\text {a, *, James V. Ray }}{ }^{\text {b, },}$, Rui Abrunhosa Gonçalves ${ }^{\text {a, }}$, , Saul Neves Jesus ${ }^{\text {c, } 3}$ \\ a School of Psychology, University of Minho, Portugal \\ ${ }^{\mathrm{b}}$ University of Central Florida, USA \\ ${ }^{c}$ Research Centre for Spatial and Organizational Dynamics, University of Algarve, Portugal
}

\section{A R T I C L E I N F O}

Article history:

Received 28 December 2016

Received in revised form 20 April 2017

Accepted 5 May 2017

Available online $\mathrm{xxx}$

Keywords:

Assessment

Callous-unemotional traits

Crime

Female juvenile delinquents

\section{A B S T R A C T}

The presence of callous-unemotional (CU) traits delineates a subgroup of male youth with severe conduct disorder and antisocial behavior, but little research has been done among female youth. Drawing on 377 female adolescents (103 selected from forensic settings and 274 selected from school settings) from Portugal, the current study is the first to simultaneously examine the psychometric properties of the Inventory of Callous-Unemotional Traits (ICU) in incarcerated female youth and community youth. The results support the use of the ICU in terms of its factor structure, and internal consistency despite the fact an item had to be removed from the Callousness dimension. Statistically significant positive associations were found with measures of psychopathic traits and aggression, as well as non-significant associations with empathy and social anxiety. Significant associations were also found with several indicators of delinquent careers including age of criminal onset, age of first contact with the law, Conduct Disorder symptoms and diagnosis, crime seriousness, previous violent offending, number of criminal charges, alcohol use, and drug use. Findings are discussed in terms of the use of the ICU among female juvenile offenders and community youths.

(C) 2016 Published by Elsevier Ltd.

\section{Introduction}

Psychopathy is a multidimensional personality disorder consisting of interpersonal (e.g., narcissistic, superficial, and manipulative), affective (e.g., callous, guiltless, and remorseless), and behavioral (impulsive and antisocial behaviors) dimensions (e.g., Hare \& Neumann, 2008). Individuals with psychopathic traits tend to show a particularly persistent and severe pattern of antisocial behavior (e.g., violence, aggression, and legal transgressions; e.g., Gendreau, Goggin, \& Smith, 2002; Hemphill, Hare, \& Wong, 1998). The extension of psychopathy to youth has become a salient goal of research (e.g., Pechorro, Jiménez, Nunes, \& Hidalgo, 2016). One potentially fruitful

\footnotetext{
? This study was supported by the Portuguese Foundation for Science and Technology (FCT; Grant SFRH/BPD/86666/2012) with co-financing of the European Social Fund (POPH/FSE), the Portuguese Ministry of Education and Science through national funds, and the PT2020 Partnership Agreement (UID/PSI/ 01662/2013).

?? We wish to thank the following Portuguese juvenile detention centers for their collaboration: Bela Vista, Navarro de Paiva, and Santa Clara.

* Corresponding author at: University of Minho, School of Psychology, Campus de Gualtar, 4710-057 Braga, Portugal.

Email addresses: ppechorro@gmail.com (P. Pechorro); james.ray@ucf.edu (J.V Ray); rabrunhosa@psi.uminho.pt (R.A. Gonçalves); snjesus@ualg.pt (S.N. Jesus)

${ }^{1}$ Postal address: Department of Criminal Justice, College of Health and Public Affairs, 12805 Pegasus Drive, Bldg. 80, Suite 311, Orlando, FL 32816, USA.

2 Postal address: University of Minho, School of Psychology, Campus de Gualtar, 4710-057 Braga, Portugal.

3 Postal address: Campus de Gambelas. 8005-139 Faro, Portugal.
}

approach to this has been through the application of the affective features of psychopathy to youth. As such, the construct of callous-unemotional (CU) traits have been found to demarcate a subgroup of conduct-disordered youth who begin engaging in problematic behaviors at a very early age and have a tendency to persist in such behaviors with increasing frequency and severity (Barry et al., 2000). Youth with CU traits are characterized as lacking remorse or guilt, having a deficient affect, and a callous disregard for others (Frick, Ray, Thornton, \& Kahn, 2014). Recently, the "With Limited Prosocial Emotions" specifier to conduct disorder was adopted into the DSM-5 in order to help guide clinical diagnoses of this subgroup of youth who tend to show a particularly stubborn responsiveness to treatment reflecting the clinical relevance of identification of these youth (Frick et al., 2014). Therefore, accurate measurement of CU traits for both clinical and research purposes has become paramount.

Given the recent downward extension of psychopathy to youth, several measures have been developed to assess the psychopathy construct including semi-structured assessments such as the Psychopathy Checklist: Youth Version (PCL: YV; Forth, Kosson, \& Hare, 2003) as well as several self-report measures including the Antisocial Process Screening Device (APSD; Frick \& Hare, 2001), the Childhood Psychopathy Scale (CPS; Lynam, 1997), and the Youth Psychopathy Index (YPI; Andershed, Kerr, Stattin, \& Levander, 2002). While these measures include subscales specifically tapping the CU component of the general psychopathy construct, the Inventory of Callous-Unemotional (ICU) traits (Kimonis et al., 2008) was designed as a stand-alone, comprehensive measure of CU traits. An extensive body of research has emerged that has provided evidence 
for the ICU as a valid measure of the CU construct (Frick et al., 2014).

Despite the emergence of such measures and the importance of $\mathrm{CU}$ traits in identifying a clinically important subgroup of antisocial youth, few studies have been concerned with the assessment of these traits among female youth. Results from a few studies have suggested that measures of $\mathrm{CU}$ traits, namely the ICU, performs equally well for both girls and boys (e.g., Essau, Sasagawa, \& Frick, 2006; Fanti, Frick, \& Georgiou, 2009; Kimonis et al., 2008). However, these studies have typically relied on mixed-gender, community-based samples of youth. More research is needed to evaluate the psychometric properties of the ICU among justice involved samples of female juveniles.

\subsection{CU traits among girls}

There is some evidence to suggest that there may be gender difference in both the level and manifestation of CU traits. It has been suggested that gender differences in socialization processes as well as biological differences between males and females may account for differences in average levels of CU traits (Hipwell et al., 2007). For instance, cultural norms shape gender specific socialization processes that tend to promote empathic concern, fearfulness, risk-taking, and emotional expression among girls (Byrnes, Miller, \& Schafer, 1999; Hipwell et al., 2007; Keenan \& Hipwell, 2005). Girls are also more likely to experience internalizing disorder (e.g., depression, anxiety, phobias) that co-occur with externalizing behaviors such as conduct disorder (e.g., Wasserman, McReynolds, Ko, Katz, \& Carpenter, 2005). Such traits are inconsistent with the concept of CU traits and suggest gender differences in pathways leading to severe conduct disorder (CD), which may account for differences in mean levels of CU traits among males and females. Indeed, research consistently finds that males show significantly higher mean levels of CU traits across different samples regardless of the measure (Declercq, Markey, Vandist, \& Verhaeghe, 2009; Essau et al., 2006; Fanti et al., 2009; Kimonis et al., 2008). Most notably, Essau et al. (2006) and Kimonis et al. (2008) compared mean scores on the ICU across males and females. Both studies found that males scored higher on the ICU total and its three subscales compared to females.

Nonetheless, a few studies have suggested that CU traits play an important role in understanding pathways to severe conduct disorder among females (Essau et al., 2006; Frick, Cornell, Barry, Bodin, \& Dane, 2003; Marsee, Silverthorn, \& Frick, 2005) and that CU traits may identify a particularly deviant subgroup of antisocial females (e.g., Hipwell et al., 2007). Importantly, a growing body of research suggests that CU traits may manifest differently among females compared to males as evidenced in gender differences in the association between $\mathrm{CU}$ traits and externalizing behaviors. For instance, Frick et al. (2003) found that $\mathrm{CU}$ traits alone (i.e., occurring without CD) are predictive of delinquency while CU traits were only predictive of delinquency when co-occurring with CD for boys. Similarly, Marsee et al. (2005) found that CU traits were associated with relational and overt aggression for females but not males. Although Essau et al. (2006) found a positive association between CU traits and conduct disorder for males and females, the association was stronger among females. Kimonis et al. (2008) also found CU traits to be associated with violent delinquency for females but not males among a detained sample of youth. Declercq et al. (2015) recently found that, among a community sample of adolescents, CU traits were associated with serious property offending for girls but not boys. Thus, it appears that there may be gender specific manifestations of CU traits and that $\mathrm{CU}$ traits may be an especially relevant factor in understanding female externalizing behaviors.
Research has also suggested that CU traits may manifest themselves differently across gender with regard to other life domains leading to unique negative outcomes for males and females. For instance, research has suggested that $\mathrm{CU}$ traits associate differently among girls and boys with regard to psychosocial impairment. One study found that the association between $\mathrm{CU}$ traits and negative peer associations was significant for girls but not boys (Essau et al., 2008). Research has also found that $\mathrm{CU}$ traits show some unique associations with certain individual characteristics for girls, particularly internalizing disorders. Among a sample of girls, Hipwell et al. (2007) found that CU traits were associated with depressed mood and generalized anxiety, an association not typically found among male or mixed-gender samples (e.g., Frick, Lilienfeld, Ellis, Loney, \& Silverthorn, 1999; Frick \& Ray, 2015; Rowe et al., 2010). Likewise, Essau et al. (2006) found that CU traits were positively associated with internalizing disorders and emotional instability for girls but not boys and also found a positive association between CU traits and experience seeking for girls but not boys. Although not thoroughly explored, these findings do suggest that associations between $\mathrm{CU}$ traits and certain external criteria differ across gender and highlight the importance of evaluating measures designed to assess CU traits among samples of females.

\subsection{Psychometric properties of the ICU}

The ICU (Kimonis et al., 2008) was developed to address the limitations of the Antisocial Process Screening Device (APSD; Frick \& Hare, 2001). That is, the ICU was designed to be a more comprehensive measure of CU traits and expanded the number of items that tapped into the CU construct from the four items of the APSD to 24 items. Based on empirical evaluations, six items were derived from each of those four items of the APSD that continued to show the most construct validity regarding CU traits (Forth et al., 2003; Frick, Bodin, \& Barry, 2000). In order to limit response bias, the ICU was developed to have an even number of positively and negatively worded items in which individuals respond using a 4-point response set (see measure description below; Kimonis et al., 2008).

Several studies examining the psychometric properties of the ICU across a diverse range of samples have found fairly consistent support for both the reliability and validity of the ICU. That is, the majority of studies examining the factor structure of the ICU support a bi-factor model in which a general $\mathrm{CU}$ factor accounts for associations among all items as well as three distinct factors (Callousness, Uncaring, and Unemotional) accounting for unique associations among groupings of items (Byrd, Kahn, \& Pardini, 2013; Ciucci, Baroncelli, Franchi, Golmaryami, \& Frick, 2014; Essau et al., 2006; Ezpeleta, de la Osa, Granero, Penelo, \& Domenech, 2013; Fanti et al., 2009; Houghton, Hunter, \& Crow, 2013; Kimonis, Branch, Hagman, Graham, \& Miller, 2013; Kimonis et al., 2008; Pechorro, Ray, Barroso, Maroco \& Gonçalves, 2016; Roose, Bijttbier, Decoene, Claes, \& Frick, 2010; Waller et al., 2015; for a 5-factor alternative solution see Feilhauer, Cima, \& Arntz, 2012). Across these studies the reliability of the ICU and its subscales has been less consistent. For instance, reliability coefficients (i.e., Cronbach's alphas) ranged from .77-.93 for the ICU total, .59-.88 for the Callousness scale, .55-.87 for the Unemotional scale, and $.47-.87$ for the Uncaring scale. The majority of studies, however, have examined the psychometric properties of the ICU among all male or mixed-gender samples and only a few studies have examined whether the $\mathrm{CU}$ construct differs across gender as measured by the ICU.

For the most part, studies suggest that there is consistency across males and females with regard to both factor structure and reliability 
of the ICU (Essau et al., 2006, Fanti et al., 2009; Houghton et al., 2013; Kimonis et al., 2008; Waller et al., 2015). Studies utilizing mixed gender samples have found adequate fit for the three bi-factor model (Fanti et al., 2009; Kimonis et al., 2008; Roose et al., 2010). The majority of those studies that have examined gender differences in the factor structure of the ICU suggest that the identified bi-factor structure is invariant across gender (Ciucci et al., 2014; Essau et al., 2006; Houghton et al., 2013; Waller et al., 2015).

Only one recent study we are aware of examined both the psychometric properties of the original full ICU and the brief ICU-12 among a detained sample of females, focusing especially on the ICU-12 (Colins, Pardini, Andershed, Hawes, \& Bijttebier, 2016). The model fit indices indicated poor fit for the proposed 3-bifactorial model of the ICU. Cronbach's alpha was adequate (above .70) for the total score and subscales, with the exception of the Unemotional subscale (.52). These authors concluded that the evidence supporting the validity of the ICU scores was generally weak, largely due to very poor functioning of the Unemotional subscale.

Research examining the association between the ICU and measures of theoretically relevant constructs has also supported the construct validity of the ICU. To start, research tends to find evidence of convergent validity between the ICU and existing measures of CU traits (Fink, Tant, Tremba, \& Kiehl, 2012; Kimonis et al., 2008; Roose et al., 2010). The ICU has also shown consistent positive associations with a variety of externalizing behaviors including CD (Essau et al., 2006; Ezpeleta et al., 2013), delinquency (Essau et al., 2006; Kimonis et al., 2008), substance use (Byrd, Loeber, \& Pardini, 2012), bullying (Munoz, Qualter, \& Padgett, 2011), and aggression (Essau et al., 2006; Fanti et al., 2009; Kimonis et al., 2008). Importantly, although there are few studies examining gender differences in the ICU and associations with external criteria, there is some evidence that unique associations with externalizing behavior emerge across gender (Ciucci et al., 2014; Essau et al., 2006; Kimonis et al., 2008). For instance, Essau et al. (2006) found that while the Callousness subscale predicted externalizing behaviors for both genders, the association between the Uncaring factor and externalizing behaviors was unique to males. Kimonis et al. (2008) also found that the Uncaring subscale was more salient in predicting externalizing outcomes for males; however, the Callousness subscale showed gender specific associations when considering specific behaviors such as reactive overt aggression and violent delinquency which both showed a positive association for girls but not boys. Ciucci et al. (2014) found several differences across gender with regard to the ICU's association with several external criteria at the subscale level. For instance, they found that the Uncaring subscale was positively related to certain types of bullying (i.e., direct and indirect) and that the Unemotional subscale was negatively related to reactive aggression for females and not males.

Consistent with the core features of psychopathy, youth with CU traits would be expected to lack empathy and have a fearless temperament (Frick, Ray, Thornton, \& Kahn, 2013). Thus, measures of CU traits should be negatively related to measures of both empathy and anxiety (or positively with measures of fearlessness). With regard to empathy, research consistently finds the expected negative association between the ICU and measures of empathy (Kimonis et al., 2008; Munoz et al., 2011; Roose et al., 2010). Essau et al. (2006) also identified a consistent negative relationship between the ICU and Agreeableness, a general personality trait consistently found to be positively associated with empathy, across genders. However, they did find that the Unemotional scale was only significantly related to Agreeableness for males and not females.
Studies have also examined the association between the ICU and measures of anxiety with findings running somewhat counter to expectations. That is, several studies have found positive associations between the ICU and measures of anxiety (Berg et al., 2013; Essau et al., 2006; Ezpeleta et al., 2011; Hawes et al., 2014; Waller et al., 2015). For instance, Ezpeleta et al. (2011) found an unexpected positive association between the Uncaring subscale of the ICU and anxiety disorder. In the only study that examined gender differences in the association between CU traits and anxiety, Berg et al. (2013) did not find evidence for gender differences regarding this association. Importantly, these studies did not account for conduct problems when examining the association between the ICU and anxiety. It has been suggested that anxiety is a result of the psychosocial impairment suffered by youth as a result of their conduct; however, those youth with $\mathrm{CU}$ traits are less distressed by their conduct problems and, in turn, show lower levels of anxiety compared to their counter parts with normative levels of CU traits (Frick et al., 1999). Thus, it is important to account for conduct problems while examining the association between CU traits and anxiety. Additionally, research has found positive associations between $\mathrm{CU}$ traits and thrill or sensation seeking (traits that should be inversely related to anxiety). For example, Essau et al. (2006) found the ICU total score to be positively related to measures of experience seeking and thrill and adventure seeking; however, they also found that that this association was somewhat isolated to females.

In sum, the majority of studies suggest support for the use of the ICU for both males and females, particularly regarding its factor structure. However, there is some evidence for gender differences with regard to the ICU and its associations with external criteria. One major limitation of past studies examining the ICU among females is that it has been mostly done among mixed-gender samples of community youth. There is a need to evaluate the psychometric properties of the ICU among a sample of females only, particularly one that is heterogeneous with regard to justice involvement.

\subsection{Current study}

The current study addresses limitations of past research by examining the psychometric properties of the ICU among a sample of females both with and without a history of justice involvement. Specifically, the current study examines the factor structure of the ICU based on confirmatory factor analysis and assesses the internal reliability of the ICU and its subscales based on Cronbach's alpha, mean inter-item correlations, and corrected item-total correlations. We also examine the convergent validity of the ICU with existing measures of CU traits as well as its criterion and divergent-related validity based on its association with a number of theoretically relevant variables. It was hypothesized that: (1) a 3-factor structure, identified by previous research, would best fit the ICU using confirmatory factor analytic methods and would show good internal consistency; (2) the ICU would exhibit expected associations with theoretically relevant outcomes used to a assess aspects of convergent validity (i.e., psychopathic traits, aggression) and discriminant validity (i.e., empathy, anxiety); and (3) the ICU scores would be significantly associated with relevant variables used to assess aspects of criterion validity, such as conduct disorder, age of crime onset, age of first contact with the law, increased crime seriousness, use of physical violence, alcohol abuse, and drug use. 


\section{Method}

\subsection{Participants}

The sample was composed of 377 female participants $(N=377$; mean age $=16.23$ years; $S D=1.38$ years; range $=14-19$ years $)$ recruited from forensic and school contexts. Of this total, 103 participants $\quad(n=103 ; \quad$ mean age $=16.41$ years; $S D=1.19$ years; range $=14-18$ years) formed the forensic sample and 274 participants $(n=274 ; \quad$ mean $\quad$ age $=16.17$ years; $\quad S D=1.44$ years; range $=14-19$ years) formed the school sample. The female inmates were recruited from the three juvenile detention centers managed by the Portuguese Ministry of Justice that admit female detainees. They were all detained by the court's decision, the harshest sanction a Portuguese juvenile court can impose. The community females were recruited from public schools of the Lisbon, Algarve, and Coimbra regions. All the participants were informed about the nature of the study and asked to voluntarily participate.

The participants were mainly Europeans (forensic sample: white Europeans $=59.2 \%$, ethnic minorities $=40.8 \%$; school sample: white Europeans $=90.1 \%$, ethnic minorities $=9.9 \%$ ) from an urban background (forensic sample $=97.1 \%$; school sample $=100 \%$ ) with a low socioeconomic status (forensic sample $=60.2 \%$; school sample $=39.1 \%$ ). The detained youths had their crime onset ( $M=12.50$ years; $S D=1.56$ years) and first contact with the law ( $M=13.27$ years; $S D=1.55$ years) early in their lives. Most were detained before they were 16 years old $(M=15.90, S D=1.04)$ due to having committed serious and violent crimes (e.g., robbery, assault).

\subsection{Measures}

The Inventory of Callous-Unemotional Traits (ICU; Essau et al., 2006; Kimonis et al., 2008) is a 24-item self-report scale designed to assess callous-unemotional traits in youth derived from the callous-unemotional (CU) subscale of the Antisocial Process Screening Device (APSD; Frick \& Hare, 2001). Each item is scored on a four-point ordinal scale (ranging from $0=$ Not at all true to $3=$ Definitely true). Scores are calculated by reverse-scoring the positively worded items and then summing the items to obtain a total score. Using confirmatory factor analysis it was possible to identify three independent factors, namely: Callousness, Unemotional, and Uncaring. All items also loaded onto a general callous-unemotional factor. Higher scores indicate an increased presence of CU traits. The Portuguese validation of the ICU (Pechorro, Hawes, Gonçalves \& Ray, 2017; Pechorro, Ray, Barroso, Maroco, \& Gonçalves, 2016) was used. Internal consistency reliability statistics for the ICU will be given later in this paper.

The self-report Antisocial Process Screening Devise (APSD-SR; Caputo, Frick, \& Brodsky, 1999; Frick \& Hare, 2001) is a multidimensional 20-item measure designed to assess psychopathic traits in adolescents. It was modeled after the Psychopathy Checklist (Forth et al., 2003; Hare, 2003; Pechorro, Barroso, Maroco, Vieira, \& Gonçalves, 2015). Each item is scored on a 3-point ordinal scale $(0=N o t$ at all true, 1 = Sometimes true, or $2=$ Definitely true). The total score, as well as each dimension score, is obtained by adding the respective items. Some more recent studies (e.g., Frick, Barry, \& Bodin, 2000) reported three main factors: Callous-Unemotional, Narcissism, and Impulsivity. Higher scores indicate higher psychopathic traits. The Portuguese version of the APSD-SR was used to analyze the convergent validity with the ICU because it is presently the most widely used self-report measure of psychopathic traits among youths
(Pechorro, Hidalgo, Nunes, \& Jiménez, 2016; Pechorro, Maroco, Poiares, \& Vieira, 2013). The internal consistency for the current study, estimated by Cronbach's alpha, was: APSD-SR total $=.77$; APSD-SR Callous-Unemotional dimension $=.51$; APSD-SR Impulsivity dimension $=.56$; and APSD-SR Narcissism dimension $=.72$.

The Youth Psychopathic Traits Inventory (YPI; Andershed et al., 2002), is a 50-item self-report measure designed to assess the core personality traits of the psychopathic personality constellation in youth aged 12 years old and up. Each item is scored on a 4-point ordinal scale (ranging from $1=$ Does not apply at all to $4=$ Applies very well). The YPI consists of 10 subscales that were designed to be in line with Cooke and Michie's (2001) three-dimensional conceptualization of the psychopathy construct, namely: the Grandiose-Manipulative dimension $(\mathrm{G}-\mathrm{M})$, the Callous-Unemotional dimension $(\mathrm{C}-\mathrm{U})$, and the Impulsive-Irresponsible dimension (I-I). More specifically, the Grandiose-Manipulative dimension consists of the Dishonest charm, Grandiosity, Lying, and Manipulation subscales; the Callous-Unemotional dimension consists of the Callousness, Unemotionality, and Remorselessness subscales; the Impulsive-Irresponsible dimension consists of the Impulsivity, Thrill-seeking, and Irresponsibility subscales. Higher scores indicate higher levels of psychopathic traits. The Portuguese version of the YPI was used to analyze the convergent validity with the ICU because research has supported a stable three-factor structure in samples of female youths (Pechorro, Andershed, Ray, Maroco, \& Gonçalves, 2015; Pechorro, Ribeiro da Silva, Rijo, Gonçalves \& Andershed, 2016; Pechorro, Ribeiro da Silva, Rijo, Gonçalves, \& Andershed, in press). The internal consistency for the current study, estimated by Cronbach's alpha, was: YPI total = .94; YPI G-M dimension = .93; YPI C-U dimension $=.78$; and YPI I-I dimension $=.87$.

The Reactive-Proactive Aggression Questionnaire (RPQ; Raine et al., 2006) is a self-report measure that distinguishes between reactive and proactive aggression. The RPQ consists of 23 items rated on a 3 -point ordinal scale $(0=$ Never, $1=$ Sometimes, $2=$ Often $)$. A total of 11 items assess reactive aggression (e.g., "Reacted angrily when provoked by others") and 12 items assess proactive aggression (e.g., "Hurt others to win a game"). Summed scores provide measures of reactive or proactive aggression, as well as total aggression. Higher scores indicate higher levels of aggression. The RPQ is appropriate for use with youth and young adults. The Portuguese version of the RPQ was used to analyze the convergent validity of the ICU because the psychopathy construct, in particular the CU traits dimension, identifies extremely violent individuals whom express both proactive and reactive aggression (Pechorro, Ray, Raine, Maroco \& Gonçalves, in press; Pechorro, Kahn, Ray, Raine, \& Gonçalves, in press). The internal consistency for the current study, estimated by Cronbach's alpha, was: $\mathrm{RPQ}$ total $=.90$; Reactive dimension $=.81$; and Proactive dimension $=.87$.

The Basic Empathy Scale (BES; Jolliffe \& Farrington, 2006) is a 20-item self-report measure designed to assess empathy in youths. The BES was developed as a concise and coherent scale with the aim of measuring two distinct factors: affective empathy and cognitive empathy. Each item is scored on a five-point ordinal scale (ranging from $1=$ Strongly disagree to $5=$ Strongly agree). Scores are calculated by reverse-scoring the positively worded items and then summing the items to obtain the total score and the factor scores. Higher scores indicate an increased presence of the associated characteristics. The Portuguese validation of the BES was used to analyze the discriminant validity of the ICU because the extension of psychopathy to youths has highlighted the core affective components of this disorder and, given that low empathy is a core feature of the construct, it would be expected to correlate negatively with empathy 
(Pechorro, Kahn, Gonçalves \& Ray, submitted for publication; Pechorro, Ray, Salas-Wright, Maroco, \& Gonçalves, 2015). The internal consistency for the current study, estimated by Cronbach's alpha, was: BES total $=.88$; Affective dimension $=.83$; and Cognitive dimension $=.91$.

The Social Anxiety Scale for Adolescents (SAS-A; La Greca \& Lopez, 1998) is an 18-item self-report scale designed to assess subjective experience of social anxiety in adolescents. Each item is rated on a 5-point ordinal scale (ranging from $1=$ Not at all to $5=$ All the time). Three distinct subscales have been identified: the Fear of Negative Evaluation (FNE) subscale reflects fears, concerns, or worries regarding negative evaluations from peers; the Social Avoidance and Distress - New (SAD-New) subscale reflects social avoidance and distress with new social situations or unfamiliar peers; the Social Avoidance and Distress - General (SAD-General) subscale reflects more generalized or pervasive social distress, discomfort, and inhibition. Scores are obtained by summing the ratings for the items comprising each subscale. The Portuguese version of the SAS-A was used to analyze the discriminant validity of the ICU because of its good psychometric properties and the fact that social anxiety generally does not overlap with the psychopathy construct (Pechorro, Ayala-Nunes, Nunes, Maroco, \& Gonçalves, 2016). The internal consistency for the current study, estimated by Cronbach's alpha, was: SAS total $=.93$; SAS-A FNE dimension $=.92$; SAS-A SAD-New dimension $=.91$; and SAS-A SAD-General dimension $=.86$.

Delinquency seriousness was assessed in the current study using the Sellin-Wolfgang Index of Crime Seriousness (ICS; Wolfgang et al., as cited in White et al., 1994). This measure guided the delinquency seriousness classification of the official court reports. Level 0 consists of no delinquency. Level 1 consists of minor delinquency committed at home such as stealing minor amounts of money from mother's purse. Level 2 consists of minor delinquency outside the home including shoplifting something worth less than 5 euros, vandalism and minor fraud (e.g. not paying bus fare). Level 3 consists of moderately serious delinquency such as any theft over 5 euros, gang fighting, carrying weapons, and joyriding. Level 4 consists of serious delinquency such as car theft and breaking and entering. Level 5 consists of having performed at least two of each of the behaviors in level 4 .

A questionnaire was constructed to describe the socio-demographic and criminal characteristics of the participants, to offer a descriptive account of the sample, and to explore the association of some of these variables (e.g., age of onset) with ICU scores. This questionnaire included variables such as participants' age, nationality, ethnic group (white Europeans vs. minorities), socioeconomic status, parental marital status, level of schooling completed, age of crime onset, age of first problem with the law, age of first incarceration, length of the conviction, taking of psychiatric drugs, use of physical violence in committing crimes, alcohol use, cannabis use, and cocaine/heroin use (these last three variables coded as 5-point ordinal variables). Socioeconomic status (SES) was measured by considering both parental level of education and profession, appropriate to the Portuguese reality (Simões, 1994). DSM-5's Conduct Disorder (CD; American Psychiatric Association, 2013) was assessed using the official diagnostic criteria (i.e., the standard method described in the DSM-5).

\subsection{Procedures}

Authorization to assess detained youths was obtained from the General Directorate of Reintegration and Prison Services of the Portuguese Ministry of Justice. The detainees, recruited from the three
Portuguese juvenile detention centers that admit females, were informed about the nature of the study and asked to voluntarily participate. The participation rate was approximately $89 \%$. Reasons for non-participation included: refusal to participate $(6 \%)$, inability to participate due to not understanding the Portuguese language $(4 \%)$, and inability to participate due to security issues (1\%). Authorization to assess youth in the school context was obtained from the General Directorate of Education of the Portuguese Ministry of Education, and parental permission was obtained for all children. The participants, students from public schools of the Lisbon, Algarve, and Coimbra regions, were informed about the nature of the study and asked to voluntarily participate. The participation rate was approximately $84 \%$. The measures were administered in an appropriate setting. Male subjects and subjects that were 21 years or older were excluded from the present study. Some of the information (e.g., socio-demographic variables) was obtained from self-reports and institutional files were also used to complement the information obtained (e.g., prior criminal activity and detentions). The first author (PhD in Psychology and $\mathrm{PhD}$ in Legal Medicine and Forensic Sciences) made the diagnosis of Conduct Disorder (American Psychiatric Association, 2013), after interviewing each youth and reviewing their institutional files.

The data were analyzed using SPSS v24 (IBM SPSS, 2016) and EQS 6.3 (Bentler \& Wu, 2015). The factor structure of the Portuguese language version of the ICU was assessed with Confirmatory Factor Analysis (CFA) performed in EQS 6.3 (Bentler \& Wu, 2015; Byrne, 2006). Goodness of fit indices were calculated, including Satorra-Bentler chi-square/degrees of freedom, comparative fit index (CFI), incremental fit index (IFI), and root mean square error of approximation (RMSEA). A chi-square/degrees of freedom value $<5$ is considered adequate, $\leq 2$ is considered good and values $=1$ are considered very good (Maroco, 2014; West, Taylor, \& Wu, 2012). A CFI $\geq .90$ and RMSEA $\leq .10$ indicate adequate fit, whereas a CFI $\geq .95$ and RMSEA $\leq .06$ indicate good model fit (Byrne, 2006). Regarding the incremental fit index, also known as Bollen's IFI, values that exceed .90 are regarded as acceptable. In terms of the Akaike Information Criterion (AIC), which measures the expected discrepancy between the true model and the hypothesized model, the model with the smallest AIC should be selected (West et al., 2012). The CFA was performed on the original scale items and only items with standardized loadings above .30 were retained (Nunnally \& Bernstein, 1994). Polychoric correlations with robust methodologies were used to perform the CFA on the ordinal items and modification indices were considered (Byrne, 2006). Pearson correlations were used to analyze associations between scale variables, Spearman correlations were used with ordinal variables, and point-biserial correlations were used to analyze associations between nominal dichotomous variables and scale variables (Leech, Barrett, \& Morgan, 2015). Cronbach's alpha values above .70 were considered to be good, mean inter-item correlations were considered good if between .15 and .50 , and corrected item-total correlations were considered satisfactory if above .20 (Clark \& Watson, 1995; Nunnally \& Bernstein, 1994).

\section{Results}

The first step in examining the psychometric properties of the ICU was to use CFA to examine the fit of previously reported factor structures for this instrument, focusing primarily on replicating the factor structures suggested. Regarding the forensic sample, no CFA was performed due to the insufficient size $(n=103)$. As shown in Table 1, the correlated three-factor model for both the school sample 
Table 1.

Goodness of fit indexes for the different models of the ICU.

\begin{tabular}{|c|c|c|c|c|c|}
\hline & $\mathrm{S}-\mathrm{B} \chi^{2} / \mathrm{df}$ & IFI & CFI & RMSEA $(90 \% \mathrm{CI})$ & AIC \\
\hline \multicolumn{6}{|l|}{ Forensic sample $^{\mathrm{a}}$} \\
\hline ICU 1-factor & - & - & - & - & - \\
\hline ICU 3-factor & - & - & - & - & - \\
\hline ICU 3-factor 2nd order & - & - & - & - & - \\
\hline Bifactor & - & - & - & - & - \\
\hline \multicolumn{6}{|l|}{ School sample } \\
\hline ICU 1-factor & 5.84 & .73 & .73 & $.13(.13-.14)$ & 966.67 \\
\hline ICU 3-factor ${ }^{b}$ & 2.92 & .90 & .90 & $.08(.08-.09)$ & 206.92 \\
\hline ICU 3-factor 2nd order & 2.87 & .76 & .75 & $.08(.07-.09)$ & 195.58 \\
\hline Bifactor & 2.72 & .80 & .79 & $.08(.07-.09)$ & 146.46 \\
\hline \multicolumn{6}{|l|}{ Total sample } \\
\hline ICU 1-factor & 7.28 & .79 & .78 & $.13(.12-.14)$ & 1214.82 \\
\hline ICU 3-factor ${ }^{b}$ & 3.65 & .91 & .91 & $.08(.08-.09)$ & 373.95 \\
\hline ICU 3-factor 2nd order & 2.86 & .84 & .84 & $.07(.06-.08)$ & 195.26 \\
\hline Bifactor & 3.20 & .83 & .83 & $.08(.07-.08)$ & 242.98 \\
\hline
\end{tabular}

Note. $\quad$ ICU $=$ Inventory of Callous-Unemotional Traits; $\mathrm{S}-\mathrm{B} \chi^{2}=$ Satorra-Bentler chi-square; $\mathrm{df}=$ degrees of freedom; IFI = Incremental Fit Index; CFI = Comparative Fit Index; RMSEA $(90 \% \mathrm{CI})=$ Root Mean Square Error of Approximation $(90 \%$ Confidence Interval); $\mathrm{AIC}=$ Akaike Information Criterion; $\mathrm{ML}=$ Maximum Likelihood.

${ }^{\text {a }}$ No CFA was performed due to the insufficient size $(n=103)$ of the forensic sample.

b Item 10 was removed due to low loadings $(<.30)$.

and the total sample obtained a better fit than the unidimensional model, the three-factor second-order model, and the bifactor model.

Presented in Table 2 are the loadings for the 3-factor first order inter-correlated structure of the ICU. As can be seen in Table 2, the factor loadings reached acceptable levels $(>.30)$ and support the groupings of items identified by prior research. However, it is important to point out that item 10 had to be removed due to low loadings $(<.30)$.

Table 2

Item loadings for the confirmatory 3 -factor first order inter-correlated structure of the ICU using the total sample.

\begin{tabular}{|c|c|c|c|}
\hline Items & $\begin{array}{l}\text { Factor } \\
1\end{array}$ & $\begin{array}{l}\text { Factor } \\
2\end{array}$ & $\begin{array}{l}\text { Factor } \\
3\end{array}$ \\
\hline \multicolumn{4}{|l|}{ Callousness } \\
\hline $\begin{array}{l}\text { 2. What } I \text { think is right and wrong is different from } \\
\text { what }[\ldots] \text {. }\end{array}$ & .34 & & \\
\hline 4. I do not care who I hurt to get what I want. & .79 & & \\
\hline 7. I do not care about being on time. & .53 & & \\
\hline 8. I am concerned about the feelings of others. (R) & .76 & & \\
\hline 9. I do not care if I get into trouble. & .63 & & \\
\hline 10. I do not let my feelings control me. (E) & - & & \\
\hline 11. I do not care about doing things well. & .61 & & \\
\hline 12. I seem very cold and uncaring to others. & .48 & & \\
\hline \multicolumn{4}{|l|}{$\begin{array}{l}\text { 18. I do not feel remorseful when I do something } \\
\text { wrong. }\end{array}$} \\
\hline 20. I do not like to put the time into doing things well. & .66 & & \\
\hline 21. The feelings of others are unimportant to me. & .75 & & \\
\hline \multicolumn{4}{|l|}{ Uncaring } \\
\hline 3. I care about how well I do at school or work. (R) & & .48 & \\
\hline 5. I feel bad or guilty when I do something wrong. (R) & & .81 & \\
\hline 13. I easily admit to being wrong. (R) & & .58 & \\
\hline 15. I always try my best. (R) & & .48 & \\
\hline 16. I apologize ("say I am sorry") to persons I hurt. (R) & & .70 & \\
\hline 17. I try not to hurt others' feelings. (R) & & .85 & \\
\hline 23. I work hard on everything I do. (R) & & .35 & \\
\hline 24. I do things to make others feel good. (R) & & .85 & \\
\hline \multicolumn{4}{|l|}{ Unemotional } \\
\hline 1. I express my feelings openly. (R) & & & .80 \\
\hline 6. I do not show my emotions to others. & & & .89 \\
\hline 14. It is easy for others to tell how I am feeling. (R) & & & .62 \\
\hline 19. I am very expressive and emotional. (R) & & & .62 \\
\hline 22. I hide my feelings from others. & & & .76 \\
\hline
\end{tabular}

Note. ICU $=$ Inventory of Callous-Unemotional Traits; $(\mathrm{R})=$ negatively worded items reverse-scored prior to analysis; $(\mathrm{E})=$ excluded item.
Presented in Table 3 are the correlations between the ICU total and its dimensions for the total sample as well as for the forensic and school samples separately. As seen in the table, these correlations were mostly moderate to high. The weakest correlations emerged among the subscales of the ICU particularly for the forensic sample. However, the latter finding may be due to low power considering that the forensic sample is much smaller. Thus, it is important to point out that the direction is consistent across the two samples.

The next step was the estimation of Cronbach's alpha, mean inter-item correlations and corrected item-total correlations range for the ICU. The results presented in Table 4 show that the ICU and its dimensions exhibited good internal consistency.

Correlations and partial-correlations (controlling for each of the dimensions of the ICU) with convergent and discriminant validity measures are presented in Table 5. As shown in the table, the correlations of the ICU and its dimensions with the APSD-SR, YPI, and the RPQ revealed mostly moderate to high statistically significant positive correlations. The discriminant validity with the BES and SAS-A revealed mostly the expected negative or low correlations. It is worth pointing out that the Unemotional subscale showed the weakest correlations and even negative partial-correlations (e.g., with APSD-SR Narcissism and YPI Impulsive-Irresponsible) in terms of convergent

Table 3

Pearson correlations matrix for the ICU.

\begin{tabular}{|c|c|c|c|c|}
\hline & ICU total & Callousness & Uncaring & Unemotional \\
\hline \multicolumn{5}{|c|}{ Forensic sample } \\
\hline ICU total & 1 & & & \\
\hline Callousness & $.83^{* * *}$ & 1 & & \\
\hline Uncaring & $.71^{* * *}$ & $.36^{* * *}$ & 1 & \\
\hline Unemotional & $.59^{* * * *}$ & $.23^{*}$ & $.22^{*}$ & 1 \\
\hline \multicolumn{5}{|l|}{ School sample } \\
\hline ICU total & 1 & & & \\
\hline Callousness & $.82^{* * *}$ & 1 & & \\
\hline Uncaring & $.73^{* * *}$ & $.38^{* * * *}$ & 1 & \\
\hline Unemotional & $.72 * * *$ & $.40^{* * *}$ & $.31^{* * *}$ & 1 \\
\hline \multicolumn{5}{|l|}{ Total sample } \\
\hline ICU total & 1 & & & \\
\hline Callousness & $.84^{* * * *}$ & 1 & & \\
\hline Uncaring & $.75^{* * *}$ & $.44^{* * * *}$ & 1 & \\
\hline Unemotional & $.65^{* * *}$ & $.32^{* * * *}$ & $.26^{* * *}$ & 1 \\
\hline
\end{tabular}

Table 4

Cronbach's alpha, mean inter-item correlation, and corrected item-total correlation range for the ICU.

\begin{tabular}{llll}
\hline & Cronbach $\alpha$ & MIIC & CITCR \\
\hline Forensic sample & & & \\
ICU total & .84 & .19 & $.17-.65$ \\
ICU Callousness & .79 & .27 & $.23-.60$ \\
ICU Uncaring & .78 & .30 & $.22-.72$ \\
ICU Unemotional & .70 & .32 & $.26-.62$ \\
School sample & & & \\
ICU total & .86 & .21 & $.22-.57$ \\
ICU Callousness & .76 & .24 & $.31-.52$ \\
ICU Uncaring & .80 & .33 & $.45-.55$ \\
ICU Unemotional & .86 & .49 & $.53-.76$ \\
Total sample & & & \\
ICU total & .86 & .21 & $.24-.57$ \\
ICU Callousness & .80 & .28 & $.31-.55$ \\
ICU Uncaring & .80 & .34 & $.38-.60$ \\
ICU Unemotional & .82 & .47 & $.50-.74$ \\
\hline
\end{tabular}

Note. ICU = Inventory of Callous-Unemotional Traits; Cronbach $\alpha=$ Cronbach's alpha; $\mathrm{MIIC}=$ Mean inter-item correlation; CITCR $=$ Corrected item-total correlation range . 
Table 5

Correlations and partial correlations of the ICU with other psychometric measures using the total sample.

\begin{tabular}{|c|c|c|c|c|}
\hline Psychometric measures & ICU total & Callousness & Uncaring & Unemotional \\
\hline APSD-SR total & $.61^{* * *}$ & $.58^{* * * *}\left(.45^{* * * *}\right)$ & $.59^{* * *}\left(.47^{* * *}\right)$ & $.16^{* *}(-.12 *)$ \\
\hline APSD-SR Callous-Unemotional & $.56^{* * * *}$ & $.37 * * *(.12 *)$ & $.56^{* * *}\left(.45^{* * *}\right)$ & $.33^{* * *}\left(.20^{* * * *}\right)$ \\
\hline APSD-SR Impulsivity & $.37^{* * * *}$ & $.41^{* * * *}\left(.33^{* * * *}\right)$ & $.36^{* * * *}(.24 * * *)$ & $.02^{n s}\left(-.17^{* *}\right)$ \\
\hline APSD-SR Narcissism & $.45^{* * *}$ & $.46^{* * * *}\left(.36^{* * *}\right)$ & $.44^{* * *}\left(.32^{* * *}\right)$ & $.05^{n s}\left(-.17^{* *}\right)$ \\
\hline YPI total & $.53^{* * *}$ & $.53^{* * *}\left(.41^{* * *}\right)$ & $.51^{* * *}\left(.39^{* * *}\right)$ & $.09^{n s}\left(-.16^{* *}\right)$ \\
\hline YPI Grandiose-Manipulative & $.45^{* * *}$ & $.45^{* * * *}\left(.34^{* * * *}\right)$ & $.43^{* * *}\left(.31^{* * *}\right)$ & $.07^{n s}\left(-.13^{*}\right)$ \\
\hline YPI Callous-Unemotional & $.53^{* * *}$ & $.46^{* * * *}\left(.30^{* * *}\right)$ & $.50^{* * *}\left(.37^{* * *}\right)$ & $.19^{* * *}\left(-.01^{n s}\right)$ \\
\hline YPI Impulsive-Irresponsible & $.43^{* * * *}$ & $.46^{* * * *}\left(.38^{* * *}\right)$ & $.42^{* * *}\left(.31^{* * *}\right)$ & $.01^{n s}\left(-.22^{* * *}\right)$ \\
\hline RPQ total & $.47^{* * *}$ & $.51^{* * * *}\left(.43^{* * *}\right)$ & $.44^{* * *}\left(.30^{* * *}\right)$ & $.04^{n s}\left(-.21^{* * *}\right)$ \\
\hline RPQ Reactive & $.44^{* * *}$ & $.44^{* * * *}\left(.33^{* * *}\right)$ & $.45^{* * *}(.34 * * *)$ & $.05^{n s}\left(-.16^{* *}\right)$ \\
\hline RPQ Proactive & $.42^{* * *}$ & $.50^{* * *}\left(.44^{* * *}\right)$ & $.35^{* * *}\left(.20^{* * *}\right)$ & $.02^{n s}\left(-.20^{* * *}\right)$ \\
\hline RPQ Reactive (controlling also for Proactive) & $.44^{* * *}(.24 * * *)$ & $.44^{* * * *}\left(.07^{n s}\right)$ & $.45^{* * *}\left(.28^{* * *}\right)$ & $.05^{n s}\left(-.05^{n s}\right)$ \\
\hline RPQ Proactive (controlling also for Reactive) & $.42^{* * *}\left(.18^{* * *}\right)$ & $.50^{* * * *}\left(.32^{* * * *}\right)$ & $.35^{* * *}\left(-.01^{n s}\right)$ & $.02^{n s}\left(-.14^{* *}\right)$ \\
\hline BES total & $-.28^{* * * *}$ & $-.13^{*}\left(.05^{n s}\right)$ & $-.29^{* * * *}\left(-.24^{* * *}\right)$ & $-.25^{* * *}\left(-.20^{* * *}\right)$ \\
\hline BES Affective & $-.23^{* * *}$ & $-.13 *\left(.00^{n s}\right)$ & $-.20^{* * *}(-.14 * *)$ & $-.22^{* * *}\left(-.17^{* *}\right)$ \\
\hline BES Cognitive & $-.22^{* * *}$ & $-.07^{n s}\left(.09^{n s}\right)$ & $-.28^{* * *}\left(-.26^{* * *}\right)$ & $-.19^{* * *}\left(-.14^{* *}\right)$ \\
\hline SAS-A total & $.01^{n s}$ & $.04^{n s}\left(.06^{n s}\right)$ & $-.06^{n s}\left(-.09^{n s}\right)$ & $.05^{n s}\left(.06^{n s}\right)$ \\
\hline SAS-A General & $.09^{n s}$ & $.06^{n s}\left(.04^{n s}\right)$ & $-.04^{n s}\left(-.10^{n s}\right)$ & $.19^{* * * *}\left(.19^{* * *}\right)$ \\
\hline SAS-A New & $.06^{n s}$ & $.05^{n s}\left(.03^{n s}\right)$ & $.01^{n s}\left(-.02^{n s}\right)$ & $.09^{n s}\left(.08^{n s}\right)$ \\
\hline SAS-A FNE & $-.06^{n s}$ & $.01^{n s}\left(.08^{n s}\right)$ & $-.10^{n s}\left(-.11^{*}\right)$ & $-.07^{n s}\left(-.06^{n s}\right)$ \\
\hline SAS-A total (controlling also for CD) & $.01^{n s}\left(.03^{n s}\right)$ & $.04^{n s}\left(.07^{n s}\right)$ & $-.06^{n s}\left(-.09^{n s}\right)$ & $.05^{n s}\left(.05^{n s}\right)$ \\
\hline SAS-A General (controlling also for CD) & $.09^{n s}\left(.10^{n s}\right)$ & $.06^{n s}\left(.01^{n s}\right)$ & $-.04^{n s}\left(-.09^{n s}\right)$ & $.19^{* * *}\left(.21^{* * *}\right)$ \\
\hline SAS-A New (controlling also for CD) & $.06^{n s}\left(.09^{n s}\right)$ & $.05^{n s}\left(.05^{n s}\right.$ & $.01^{n s}\left(-.01^{n s}\right)$ & $.09^{n s}\left(.07^{n s}\right)$ \\
\hline SAS-A FNE (controlling for also CD) & $-.06^{n s}\left(-.06^{n s}\right)$ & $.01^{n s}\left(.08^{n s}\right)$ & $-.10^{n s}\left(-.11^{*}\right)$ & $-.07^{n s}\left(-.06^{n s}\right)$ \\
\hline
\end{tabular}

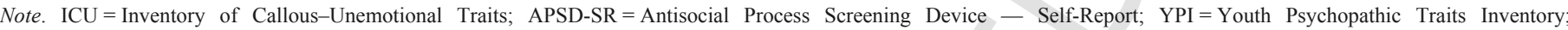

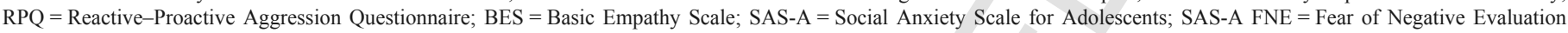
dimension; $\mathrm{CD}=$ Conduct Disorder diagnosis. Correlations in parentheses represent partial correlations controlling for the other two subscales except where otherwise noted.

Partial correlations controlling for the dimensions of the ICU are given in parenthesis.

$n s=$ non-significant.

**** Significant at the .001 level.

** Significant at the .01 level.

* Significant at the .05 level.

validity and also an unexpected positive correlation/partial-correlation with generalized anxiety.

Presented in Table 6 are the correlations and partial-correlations (controlling for each of the dimensions of the ICU) with other vari-

Table 6

Correlations and partial correlations of the ICU with other variables using the total sample.

\begin{tabular}{lllll}
\hline Variables & ICU total & Callousness & Uncaring & Unemotional \\
\hline Age & $.08^{n s}$ & $-.09^{n s}\left(.06^{n s}\right)$ & $.09^{n s}\left(.06^{n s}\right)$ & $-.02^{n s}\left(-.05^{n s}\right)$ \\
Education (years) & $-.21^{* * *}$ & $-.20^{* * *}\left(-.13^{*}\right)$ & $-.24^{* * * *}\left(-.18^{* *}\right)$ & $-.02^{n s}\left(-.08^{n s}\right)$ \\
SES & $-.07^{n s}$ & $-.10^{n s}\left(.03^{n s}\right)$ & $-.04^{n s}\left(.06^{n s}\right)$ & $-.01^{n s}\left(.09^{n s}\right)$ \\
Psychiatric drugs & $.29^{* * *}$ & $.25^{* * *}\left(.15^{* *}\right)$ & $.28^{* * *}\left(.19^{* * *}\right)$ & $.10^{n s}\left(-.01^{n s}\right)$ \\
ACO & $-.14^{n s}$ & $-.16^{n s}\left(-.13^{n s}\right)$ & $-.20^{*}\left(-.18^{*}\right)$ & $.10^{n s}\left(.19^{*}\right)$ \\
AFPL & $-.31^{* *}$ & $-.25^{* *}\left(-.15^{n s}\right)$ & $-.27^{* * *}\left(-.19^{*}\right)$ & $-.12^{n s}\left(-.01^{n s}\right)$ \\
AFIJDC & $-.25^{*}$ & $-.12^{n s}\left(.04^{n s}\right)$ & $-.28^{* *}\left(-.25^{*}\right)$ & $-.17^{n s}\left(-.11^{n s}\right)$ \\
CD symptoms & $.39^{* * *}$ & $.44^{* * *}\left(.36^{* * *}\right)$ & $.38^{* * * *}\left(.26^{* * *}\right)$ & $.01^{n s}\left(-.20^{* * *}\right)$ \\
CD diagnosis & $.35^{* * *}$ & $.39^{* * *}\left(.31^{* * * *}\right)$ & $.33^{* * * *}\left(.21^{* * *}\right)$ & $.02^{n s}\left(-15^{* *}\right)$ \\
ICS & $.41^{* * *}$ & $.45^{* * *}\left(.37^{* * *}\right)$ & $.37^{* * *}\left(.23^{* * *}\right)$ & $.03^{n s}\left(-.17^{* *}\right)$ \\
PVC & $.38^{* * *}$ & $.40^{* * *}\left(.31^{* * *}\right)$ & $.36^{* * *}\left(.24^{* * *}\right)$ & $.04^{n s}\left(-.14^{*}\right)$ \\
NCC & $.29^{* * *}$ & $.20^{* *}\left(.08^{n s}\right)$ & $.23^{*}\left(.13^{n s}\right)$ & $.20^{*}\left(.12^{n s}\right)$ \\
Alcohol & $.28^{* * *}$ & $.34^{* * * *}\left(.29^{* * *}\right)$ & $.30^{* * * *}\left(15^{*}\right)$ & $-.05^{n s}\left(-.17^{* * *}\right)$ \\
Cannabis & $.33^{* * *}$ & $.31^{* * *}\left(.25^{* * *}\right)$ & $.34^{* * * *}\left(.17^{* *}\right)$ & $.02^{n s}\left(-.14^{*}\right)$ \\
Cocaine/heroin & $.29^{* * *}$ & $.29^{* * *}\left(.24^{* * *}\right)$ & $.28^{* * *}\left(.14^{*}\right)$ & $.01^{n s}\left(-.09^{n s}\right)$ \\
\hline
\end{tabular}

Note. ICU = Inventory of Callous-Unemotional Traits; ACO = Age of crime onset; $\mathrm{AFPL}=$ Age of first problem with the law; AFIJDC $=$ Age of first incarceration into a Juvenile Detention Center; CD symptoms $=$ DSM-5 Conduct Disorder symptoms scored as a scale; CD diagnosis = DSM-5 Conduct Disorder diagnosis; ICS = Index of Crime Seriousness; PVC $=$ Previous violent crimes; $\mathrm{NCC}=$ Number of criminal charges.

Partial correlations controlling for the dimensions of the ICU are given in parenthesis $n s=$ non-significant

*** Significant at the .001 level.

** Significant at the .01 level.

* Significant at the .05 level. ables (e.g., age, years of education). Statistically significant correlations were found between the ICU and many of the variables analyzed (e.g., age of first problem with the law, CD diagnosis, crime seriousness). Interestingly, the Unemotional subscale also presented the weakest associations, this time in terms of criterion-related validity, with some partial-correlations being unexpectedly negative (e.g., with $\mathrm{CD}$, crime seriousness).

\section{Discussion}

The main aim of this study was to analyze the psychometric properties of the ICU among incarcerated female juvenile offenders and community youths. It was hypothesized that: (1) a 3-factor structure, identified by previous research, would best fit the ICU using confirmatory factor analytic methods and would show good internal consistency; (2) the ICU would exhibit expected associations with theoretically relevant outcomes used to a assess aspects of convergent validity (i.e., psychopathic traits, aggression) and discriminant validity (i.e., empathy, anxiety); and (3) the ICU scores would be significantly associated with relevant variables used to assess aspects of criterion validity, such as conduct disorder, age of crime onset, age of first contact with the law, increased crime seriousness, use of physical violence, alcohol abuse, and drug use.

In the forensic sample no CFA was performed due to the insufficient sample size (see Kline, 2011; Muthén \& Muthén, 2002). The ICU total and its dimensions reached the recommended Cronbach's $\alpha$ above .70 (Nunnally \& Bernstein, 1994). These values of Cronbach's alpha were better than the ones obtained by Colins et al. (2016) among detained female youths. Regarding the mean inter-item correlations, the ICU total and its dimensions were all within the recommended value range of .15-.50 (Clark \& Watson, 1995; Domino \& 
Domino, 2006), revealing adequate heterogeneity between the items. In terms of the corrected item-total correlation range, the ICU total failed to reach the minimum recommended value of .20 (Kaplan \& Saccuzzo, 2013; Nunnally \& Bernstein, 1994), suggesting weak associations between some items and the total scale among this sample. This, however, may reflect the multidimensional nature of the ICU given that the corrected item-total correlations corresponding to each of the three dimensions of the ICU were all above the .20 value.

In the school sample, in terms of the CFA, several fit indices suggested that the three-factor inter-correlated model presented the best fit, but item 10 ("I do not let my feelings control me") was removed due to the low loading it obtained. The removal of this item due to low loadings problems is consistent with prior research among male samples and mixed gender samples (e.g., Lopez-Romero, Gomez-Fraguela, \& Romero, 2015; Kimonis et al., 2008; Ray, Frick, Thornton, Steinberg, \& Cauffman, 2016). As in the forensic sample, we evaluated the internal consistency of the ICU and its dimensions based on several indices including Cronbach's $\alpha$ level, the mean inter-item correlations, and the corrected item-total correlation range. All three measures of internal consistency suggested that the ICU and each of the dimensions had good internal reliability based on minimum recommended values (Kaplan \& Saccuzzo, 2013; Nunnally $\&$ Bernstein, 1994). Again, these values were better than the ones obtained by Colins et al. (2016) among detained female youths.

In the total sample, the three-factor inter-correlated model also presented the best fit, but item 10 was also removed due to the low loading it obtained. Good values were also found regarding the internal consistency of the ICU and its dimensions, the mean inter-item correlations, and the corrected item-total correlation range. The correlations between the ICU total and its dimensions showed mostly moderate to high statistically significant positive associations, with the weakest correlations being found between the Unemotional dimension and the other two dimensions of the ICU among the forensic sample. These findings are in line with previous studies, which have found moderate correlations among the dimensions with particularly weak correlations among the Unemotional scale (e.g., Colins et al., 2016; Essau et al., 2006; Kimonis et al., 2008).

The convergent validity of the ICU and its dimensions with the APSD-SR, the YPI, and the RPQ revealed mostly moderate to high statistically significant positive correlations demonstrating the expected overlap in line with the ones found in previous studies (e.g., Lopez-Romero et al., 2015; Pihet, Etter, Schmid, \& Kimonis, 2015; Roose et al., 2010). The exception was the Unemotional dimension, which revealed mostly non-significant correlations and even unexpected negative partial-correlations. This suggests that the Unemotional dimension should be used with caution because it may not be tapping the $\mathrm{CU}$ construct. More work at the item-level is necessary to inform revisions of the Unemotional subscale in order to better capture the intended construct (see Colins et al., 2016). With regard to discriminant validity (AERA, APA, \& NCME, 2014; Kaplan $\&$ Saccuzzo, 2013), for the most part, the associations revealed the expected non-significant or low negative correlations with empathy (e.g., Kimonis et al., 2008; Munoz et al., 2011; Roose et al., 2010) and anxiety (e.g., Berg et al., 2013; Essau et al., 2006; Ezpeleta et al., 2011; Waller et al., 2015).

The analyses also showed moderate to high associations between the ICU and several criterion related parameters such as criminal onset, CD symptoms and diagnosis, crime seriousness, history of previous violent crime, number of criminal charges and substance use. These findings are consistent with previous studies using samples of males (e.g., Byrd et al., 2013; Kahn, Byrd, \& Pardini, 2013) and mixed gender samples (e.g., Lopez-Romero et al., 2015;
McMahon, Witkiewitz, \& Kotler, 2010). Again, the exception was the Unemotional dimension, which revealed mostly non-significant correlations and negative partial-correlations. These criterion-related and convergent validity problems of the Unemotional dimension suggest that the self-reported version items of this subscale are poor indicators of an overarching CU factor (see Hawes et al., 2014).

Like their male peers, females in the forensic and school context who display more CU features are likely to exhibit generalized problem behaviors that are associated with juvenile justice system involvement. The high prevalence of conduct disorder $(85.4 \%)$ found in the current forensic sample was higher than those typically found among forensic samples composed of female youths (Sevecke \& Kosson, 2010). This was not a surprise due to the fact that youth incarceration is the harshest sanction a Portuguese juvenile court can impose and this sanction is reserved for the more serious cases. These findings are consistent with other studies of youth where CU traits were robustly associated with arrest, probation, incarceration, total offending, and overall criminal justice system involvement (Frick et al., 2014). In sum, these findings are mostly consistent with other previous research using male adolescent detainees (e.g., Lopez-Romero et al., 2014; Pihet et al., 2015).

Our findings should be considered in light of several limitations. First, we must mention that only the self-report version of the ICU was used and future research should attempt to replicate these results using multiple informants (i.e., parent-report, teacher-report). Second, the small size of the forensic sample excluded the use of CFA among this specific sample. Third, further psychometric procedures are needed and must be done in the near future (e.g., cross-validation, temporal stability).

$\mathrm{CU}$ traits have been shown to delineate a unique subgroup of children and adolescents with severe and persistent conduct problems that seem to have unique etiological origins (e.g., Hawes et al., 2014; Waller et al., 2015). Considering the costs that these children and adolescents create in terms of their behaviors and collateral effects on other people and society as a whole, we hope that our study may promote future research and a more generalized use of the ICU among different cultures, ethnicities and samples. Our findings are consistent with that of previous studies suggesting support for the use of the ICU for both males and females (e.g., Essau et al., 2006; Fanti et al., 2009; Kimonis et al., 2008) in terms of its psychometric properties. One major limitation of past studies examining the ICU among females is that it has been done among mixed-gender samples of community youth. Our research addressed this major limitation of past studies by being one of the first to examine the psychometric properties of the ICU among a sample of females both with and without a history of justice involvement. That is, among this sample of females, we found support for the three-factor structure of the ICU, the internal consistency of the ICU, and convergent and divergent validity of the ICU and is dimensions. Additionally, the findings from the current study raise important concerns regarding the Unemotional subscale of the ICU that are consistent with prior research among male and mixed-gender samples that requires further investigation. In sum, we were able to provided clear evidence supporting the ICU as a valid measure of CU traits in a Portuguese sample referred and non-referred female youth.

\section{Uncited references}

Christian et al., 1997

Feilhauer and Cima, 2013

Frick, 2004

Hambleton et al., 2005 
Kimonis et al., 2015

Lahey, 2014

Latzman et al., 2013

Rutter, 2012

\section{References}

American Educational Research Association (AERA), American Psychological Association (APA), National Council for Measurement in Education (NCME), 2014 Standards for educational and psychological testing. AERA, Washington, DC.

American Psychiatric Association, 2013. Diagnostic and statistical manual of mental disorders, 5th ed. Author, Washington, DC

Andershed, H., Kerr, M., Stattin, H., Levander, S., 2002. Psychopathic traits in non-referred youths: Initial test of a new assessment tool. In: Blaauw, E., Sheridan, L. (Eds.), Psychopaths: Current international perspectives. Elsevier, Haag, Netherlands, pp. 131-158.

Barry, C.T., Frick, P.J., DeShazo, T.M., McCoy, M.G., Ellis, M., Loney, B.R., 2000 The importance of callous-unemotional traits for extending the concept of psychopathy to children. Journal of Abnormal Psychology 109, 335-340. http://dx. doi.org/10.1037/0021-843X.109.2.335.

Bentler, P., Wu, E., 2015. Supplement to EQS 6.3 for Windows user's guide. Multivariate Software, Temple City, CA

Berg, J.B., Lilienfeld, S.O., Reddy, S.D., Latzman, R.D., Roose, A., Craighead, L.W., et al., 2013. The inventory of callous and unemotional traits: A construct-validational analysis in an at-risk sample. Assessment 20, 532-544. http://dx.doi.org/10. $1177 / 1073191112474338$

Byrd, A.L., Kahn, R.E., Pardini, D.A., 2013. A validation of the Inventory of Callous-Unemotional Traits in a community sample of young adult males. Journal of Psychopathology and Behavioral Assessment 35, 20-34. http://dx.doi.org/10.1007 10862-012-9315-4.

Byrd, A.L., Loeber, R., Pardini, D.A., 2012. Understanding desisting and persisting forms of delinquency: The unique contributions of disruptive behavior disorders and interpersonal callousness. Journal of Child Psychology and Psychiatry 53, 371-380. http://dx.doi.org/10.1111/j.1469-7610.2011.02504.x

Byrne, B., 2006. Structural equation modeling with EQS: Basic concepts, applications, and programming. Lawrence Erlbaum Associates, Mahwah, NJ.

Byrnes, J.P., Miller, D.C., Schafer, W.D., 1999. Gender differences in risk taking: A meta-analysis. Psychological Bulletin 125, 367-383. http://dx.doi.org/10.1037/ 0033-2909.125.3.367.

Caputo, A., Frick, P., Brodsky, S., 1999. Family violence and juvenile sex offending. Criminal Justice and Behavior 26, 338-356. http://dx.doi.org/10.1177/ 0093854899026003004

Christian, R.E., Frick, P.J., Hill, N.L., Tyler, L., Frazer, D.R., 1997. Psychopathy and conduct problems in children: II Implications for subtyping children with conduct problems. Journal of the American Academy of Child and Adolescent Psychiatry 36, 233-241. http://dx.doi.org/10.1097/00004583-199702000-00014.

Ciucci, E., Baroncelli, A., Franchi, M., Golmaryami, F.N., Frick, P.J., 2014. The association between callous-unemotional traits and behavioral and academic adjustment in children: Further validation of the Inventory of Callous-Unemotional Traits. Journal of Psychopathology and Behavioral Assessment 36, 189-200. http //dx.doi.org/10.1007/s10862-013-9384-z.

Clark, L., Watson, D., 1995. Constructing validity: Basic issues in objective scale development. Psychological Assessment 7, 309-319. http://dx.doi.org/10.1037/ 1040-3590.7.3.309.

Colins, O., Pardini, D., Andershed, H., Hawes, S., Bijttebier, P., 2016. Psychometric properties of the original and short form of the Inventory of Callous-Unemotional Traits in detained female adolescents. Child Psychiatry and Human Development 47, 679-690. http://dx.doi.org/10.1007/s10578-015-0601-8.

Cooke, D., Michie, C., 2001. Refining the construct of psychopathy: Towards a hierarchical model. Psychological Assessment 13, 171-188. http://dx.doi.org/10.1037 1040-3590.13.2.171

Declercq, F., Markey, S., Vandist, K., Verhaeghe, P., 2009. The Youth Psychopathic Trait Inventory: Factor structure and antisocial behaviour in non-referred 12-17-year-olds. Journal of Forensic Psychiatry \& Psychology 20, 577-594. http:// dx.doi.org/10.1080/14789940802651757.

Essau, C., Sasagawa, S., Frick, P., 2006. Callous-unemotional traits in community sample of adolescents. Assessment 13, 454-469. http://dx.doi.org/10.1177/ 1073191106287354

Ezpeleta, L., de la Osa, N., Granero, R., Penelo, E., Domenech, J.M., 2013. Inventory of Callous-Unemotional Traits in a community sample of preschoolers. Journal of Clinical Child \& Adolescent Psychology 42, 91-105. http://dx.doi.org/10.1080/ 15374416.2012 .734221

Fanti, K.A., Frick, P.J., Georgiou, S., 2009. Linking callous-unemotional traits to instrumental and non-instrumental forms of aggression. Journal of Psychopathology and Behavioral Assessment 31, 285-298. http://dx.doi.org/10.1007/ s10862-008-9111-3.
Feilhauer, J., Cima, M., 2013. Youth psychopathy: Differential correlates of callous-unemotional traits, narcissism, and impulsivity. Forensic Science International 224, 1-7. http://dx.doi.org/10.1016/j.forsciint.2012.10.016.

Feilhauer, J., Cima, M., Arntz, A., 2012. Assessing callous-unemotional traits across different groups of youths: Further cross-cultural validation of the Inventory of Callous-Unemotional Traits. International Journal of Law and Psychiatry 35, 251-262. http://dx.doi.org/10.1016/j.ijlp.2012.04.002.

Fink, B.C., Tant, A.S., Tremba, K., Kiehl, K.A., 2012. Assessment of psychopathic traits in an incarcerated adolescent sample: A methodological comparison. Journal of Abnormal Child Psychology 40, 971-986. http://dx.doi.org/10.1007/ s10802-012-9614-y.

Forth, A.E., Kosson, D., Hare, R.D., 2003. The Hare PCL: youth version. Multi-Health Systems, Toronto, Ontario, Canada.

Frick, P. J. (2004). The Inventory of Callous-Unemotional Traits. New Orleans: The University of New Orleans. (Unpublished rating scale)

Frick, P., Barry, C., Bodin, S., 2000. Applying the concept of psychopathy to children: Implications for the assessment of antisocial youth. In: Gacono, C. (Ed.), The clinical and forensic assessment of psychopathy: A practitioner's guide, Lawrence Erlbaum, Mahwah, NJ, pp. 1-24.

Frick, P.J., Bodin, S.D., Barry, C.T., 2000. Psychopathic traits and conduct problems in community and clinic-referred samples of children: Further development of the Psychopathy Screening Device. Psychological Assessment 12, 382-393. http://dx. doi.org/10.1037/1040-3590.12.4.382.

Frick, P.J., Cornell, A.H., Barry, C.T., Bodin, S.D., Dane, H.A., 2003. Callous-unemotional traits and conduct problems in the prediction of conduct problem severity, aggression, and self-report of delinquency. Journal of Abnormal Child Psychology 31, 457-470. http://dx.doi.org/10.1023/A:1023899703866.

Frick, P., Hare, R., 2001. THE Antisocial Process Screening Device (APSD): Technical manual. Multi-Health Systems, Toronto, ON

Frick, P.J., Lilienfeld, S.O., Ellis, M., Loney, B., Silverthorn, P., 1999. The association between anxiety and psychopathy dimensions in children. Journal of Abnormal Child Psychology 27, 383-392. http://dx.doi.org/10.1023/A:1021928018403.

Frick, P.J., Ray, J.V., 2015. Evaluating callous-unemotional traits as a personality construct. Advance online publication. Journal of Personality 83, 710-722. http://dx. doi.org/10.1111/jopy.12114.

Frick, P., Ray, J., Thornton, L., Kahn, R., 2013. A developmental psychopathology approach to understanding callous-unemotional traits in children and adolescents with serious conduct problems. Journal of Child Psychology and Psychiatry 55, 532-548. http://dx.doi.org/10.1111/jcpp.12152.

Frick, P.J., Ray, J.V., Thornton, L.C., Kahn, R.E., 2014. Can callous-unemotional traits enhance the understanding, diagnosis, and treatment of serious conduct problems in children and adolescents? A comprehensive review. Psychological Bulletin 140, 1-57. http://dx.doi.org/10.1037/a0033076.

Gendreau, P., Goggin, C., Smith, P., 2002. Is the PCL-R really the "unparalleled" measure of offender risk? A lesson in knowledge cumulation. Criminal Justice and Behavior 29, 397-426. http://dx.doi.org/10.1177/0093854802029004004.

Hambleton, R., Merenda, P., Spielberger, C., 2005. Adapting educational and psychological tests for cross-cultural assessment. Lawrence Erlbaum Associates, Mahwah, NJ.

Hawes, S.W., Byrd, A.L., Henderson, C.E., Gazda, R.L., Burke, J.D., Loeber, R., Pardini, D.A., 2014. Refining the parent-reported Inventory of Callous-Unemotional Traits in boys with conduct problems. Psychological Assessment 26 (1), 256-266. http://dx.doi.org/10.1037/a0034718.

Hemphill, J.F., Hare, R.D., Wong, S., 1998. Psychopathy and recidivism: A review. Legal and Criminological Psychology 3, 139-170. http://dx.doi.org/10.1111/j. 2044-8333.1998.tb00355.x

Hipwell, A.E., Pardini, D.A., Loeber, R., Sembower, M., Keenan, K., Stouthamer-Loeber, M., 2007. Callous-unemotional behaviors in young girls: Shared and unique effects relative to conduct problems. Journal of Clinical Child and Adolescent Psychology 36, 293-304. http://dx.doi.org/10.1080/15374410701444165.

Houghton, S., Hunter, S., Crow, J., 2013. Assessing callous unemotional traits in children aged 7-to 12-years: A confirmatory factor analysis of the inventory of callous unemotional traits. Journal of Psychopathology and Behavioral Assessment 35, 215-222. http://dx.doi.org/10.1007/s10862-012-9324-3.

IBM SPSS, 2016. IBM SPSS statistics base 24. SPSS, Chicago, IL.

Kahn, R.E., Byrd, A.L., Pardini, D.A., 2013. Callous-unemotional traits robustly predict future criminal offending in in young men. Law and Human Behavior 37, 87-97. http://dx.doi.org/10.1037/b0000003.

Kaplan, R., Saccuzzo, D., 2013. Psychological testing: Principles, applications, and issues, 8th ed. Wadsworth, Cengage Learning, Belmont, CA.

Keenan, K., Hipwell, A., 2005. Preadolescent clues to understanding depression in girls. Clinical Child and Family Psychology Review 8, 89-105. http://dx.doi.org/ 10.1007/s10567-005-4750-3

Kimonis, E., Branch, J., Hagman, B., Graham, N., Miller, C., 2013. The psychometric properties of the Inventory of Callous-Unemotional Traits in an undergraduate sample. Psychological Assessment 25 (1), 84-93. http://dx.doi.org/10.1037/ a0029024.

Kimonis, E., Fanti, K., Frick, P., Moffitt, T., Essau, C., Bijttebier, P., Marsee, A., 2015. Using self-reported callous-unemotional traits to cross-nationally assess the 
DSM-5 'With Limited Prosocial Emotions' specifier. Journal of Child Psychology and Psychiatry 56, 1249-1261. http://dx.doi.org/10.1111/jcpp.12357.

Kimonis, E., Frick, P., Skeem, J., Marsee, M., Cruise, K., Munoz, L., ... Morris, A., 2008. Assessing callous-unemotional traits in adolescent offenders: Validation of the Inventory of Callous-Unemotional Traits. International Journal of Law and Psychiatry 31, 241-252. http://dx.doi.org/10.1016/j.ijlp.2008.04.002.

Kline, R.B., 2011. Principles and practice of structural equation modeling, 3rd ed. Guilford Press, New York.

La Greca, A., Lopez, N., 1998. Social anxiety among adolescents: Linkages with peer relations and friendships. Journal of Clinical Child Psychology 26, 83-94.

Lahey, B.B., 2014. What we need to know about callous-unemotional traits: Comment on Frick, Ray, Thornton, and Kahn (2014). Psychological Bulletin 140, 58-63. http://dx.doi.org/10.1037/a0033387.

Latzman, R.D., Lilienfeld, S.O., Latzman, N.E., Clark, L.A., 2013. Exploring callous and unemotional traits in youth via trait personality: An eye toward DSM-5. Personality Disorders: Theory, Research, and Treatment 4, 191-202. http://dx.doi.org/ 10.1037/a0000001.

Leech, N., Barrett, K., Morgan, G., 2015. SPSS for intermediate statistics: Use and interpretation, 5th ed. Routledge, New York.

Lopez-Romero, L., Gomez-Fraguela, X., Romero, E., 2015. Assessing callous-unemotional traits in a Spanish sample of institutionalized youths: The Inventory of Callous-Unemotional Traits. Journal of Psychopathology and Behavioral Assessment 37, 392-406. http://dx.doi.org/10.1007/s10862-014-9469-3.

Lynam, D.R., 1997. Pursuing the psychopath: Capturing the fledgling psychopath in a nomological net. Journal of Abnormal Psychology 106, 425-438. http://dx.doi.org/ 10.1037/0021-843X.106.3.425

Maroco, J., 2014. Análise de Equações Estruturais: Fundamentos teóricos, software \& aplicações [Structural equations analysis: Theoretical foundations, software and applications]. ReportNumber, Pero Pinheiro.

Marsee, M.A., Silverthorn, P., Frick, P.J., 2005. The association of psychopathic traits with aggression and delinquency in nonreferred boys and girls. Behavioral Sciences $\&$ the Law 23, 803-817. http://dx.doi.org/10.1002/bsl.662.

McMahon, R.J., Witkiewitz, K., Kotler, J.S., 2010. Predictive validity of callous-unemotional traits measured in early adolescence with respect to multiple antisocial outcomes. Journal of Abnormal Psychology 119, 752-763. http://dx.doi.org/10. 1037/a0020796.

Munoz, L.C., Qualter, P., Padgett, G., 2011. Empathy and bullying: Exploring the influence of callous-unemotional traits. Child Psychiatry and Human Development 42, 183-196. http://dx.doi.org/10.1007/s10578-010-0206-1.

Muthén, L.K., Muthén, B.O., 2002. How to use a Monte Carlo study to decide on sample size and determine power. Structural Equation Modeling 9, 599-620.

Nunnally, J., Bernstein, I., 1994. Psychometric theory. McGraw-Hill, New York, NY.

Pechorro, P., Andershed, H., Ray, J., Maroco, J., Gonçalves, R., 2015. Validation of the Youth Psychopathic Traits Inventory and Youth Psychopathic Traits Inventory - Short form among incarcerated juvenile delinquents. Journal of Psychopathology and Behavioral Assessment 37, 576-586. http://dx.doi.org/10.1007/ s10862-015-9490-1.

Pechorro, P., Ayala-Nunes, L., Nunes, C., Maroco, J., Gonçalves, R., 2016. The Social Anxiety Scale for Adolescents: Measurement invariance and psychometric properties among a school sample of Portuguese youths. Child Psychiatry and Human Development 47, 975-984. http://dx.doi.org/10.1007/s10578-016-0627-6.

Pechorro, P., Barroso, R., Maroco, J., Vieira, R., Gonçalves, R., 2015. Psychometric properties of the Psychopathy Checklist: Youth version among Portuguese juvenile delinquents. International Journal of Offender Therapy and Comparative Criminology 59, 1322-1337. http://dx.doi.org/10.1177/0306624X14535558.

Pechorro, P., Hawes, S., Gonçalves, R., Ray, J., 2017. Psychometric properties of the Inventory of Callous-Unemotional Traits short version (ICU-12) among detained female juvenile offenders and community youths. Psychology, Crime \& Law 23, 221-239. http://dx.doi.org/10.1080/1068316X.2016.1239724.

Pechorro, P., Hidalgo, V., Nunes, C., Jiménez, L., 2016. Confirmatory factor analysis of the Antisocial Process Screening Device: Self-report among incarcerated male juvenile offenders. International Journal of Offender Therapy and Comparative Criminology 60, 1856-1872. http://dx.doi.org/10.1177/0306624X15588903.

Pechorro, P. Jiménez, L., Nunes, C., \& Hidalgo, V. (2016a). El constructo de psicopatía y su aplicación en niños y adolescentes [The construct of psychopathy and its application to children and adolescents]. In C. Poiares, J. Urra, J. A. Echauri, \& A. Martinez (Coordinadores), La Psicología Jurídica en Iberoamérica: Nuevos aportes de la Psicología Jurídica 2 (pp. 55-66). Colección Psicología Jurídica EOS.
Pechorro, P., Kahn, R., Gonçalves, R.A., Ray, J., 2017. Psychometric properties of Basic Empathy Scale among female juvenile delinquents and school youths. International Journal of Law and Psychiatry (submitted for publication).

Pechorro, P., Kahn, R., Ray, J., Raine, A., Gonçalves, R.A., 2017. Psychometric properties of the Reactive-Proactive Aggression Questionnaire among detained female juvenile delinquents and community youths. Criminal Justice and Behaviorhttp:// dx.doi.org/10.1177/0093854816686395 (Advance online publication, in press).

Pechorro, P., Ray, J., Barroso, R., Maroco, J., Gonçalves, R., 2016. Validation of the Inventory of Callous-Unemotional Traits among Portuguese juvenile delinquents. International Journal of Offender Therapy and Comparative Criminology 60 , 349-365. http://dx.doi.org/10.1177/0306624X14551256.

Pechorro, P., Ray, J., Raine, A., Maroco, J., Gonçalves, R., 2017. The Reactive-Proactive Aggression Questionnaire: Validation among a Portuguese sample of incarcerated juvenile delinquents. Journal of Interpersonal Violencehttp://dx.doi.org/10 $1177 / 0886260515590784$ (Advance online publication, in press).

Pechorro, P., Ray, J., Salas-Wright, C., Maroco, J., Gonçalves, R., 2015. Adaptation of the Basic Empathy Scale among a Portuguese sample of incarcerated juvenile offenders. Psychology, Crime \& Law 21, 699-714. http://dx.doi.org/10.1080/ 1068316X.2015.1028546.

Pechorro, P., Ribeiro da Silva, D., Rijo, D., Gonçalves, R.A., Andershed, H., 2016. The Youth Psychopathic Traits Inventory: Measurement invariance and psychometric properties among Portuguese youths. International Journal of Environmental Research and Public Health 13, 852. http://dx.doi.org/10.3390/ijerph13090852.

Pechorro, P., Ribeiro da Silva, D., Rijo, D., Gonçalves, R.A., Andershed, H., 2017. Psychometric properties and measurement invariance of the Youth Psychopathic Traits Inventory - Short among Portuguese youths. Journal of Psychopathology and Behavioral Assessmenthttp://dx.doi.org/10.1007/s10862-017-9597-7 (Advance online publication, in press).

Pihet, S., Etter, S., Schmid, M., Kimonis, E., 2015. Assessing callous-unemotional traits in adolescents: Validity of the Inventory of Callous-Unemotional Traits across gender, age, and community/institutionalized status. Journal of Psychopathology and Behavioral Assessment 37, 407-421. http://dx.doi.org/10.1007/ s10862-014-9472-8.

Raine, A., Dodge, K., Loeber, R., Gatzke-Kopp, L., Lynam, D., Reynolds, C., et al., 2006. The Reactive-Proactive Aggression Questionnaire: Differential correlates of reactive and proactive aggression in adolescent boys. Aggressive Behavior 32, 159-171. http://dx.doi.org/10.1002/ab.20115.

Ray, J.V., Frick, P., Thornton, L., Steinberg, L., Cauffman, E., 2016. Positive and negative item wording and its influence on the assessment of callous-unemotional traits. Psychological Assessment 28, 394-404. http://dx.doi.org/10.1037/ pas0000183

Roose, A., Bijttbier, P., Decoene, S., Claes, L., Frick, P.J., 2010. Assessing the affective features of psychopathy in adolescence: A further validation of the Inventory of Callous and Unemotional Traits. Assessment 17, 44-57. http://dx.doi.org/10. $1177 / 1073191109344153$.

Rowe, R., Maughan, B., Moran, P., Ford, T., Briskman, J., Goodman, R., 2010. The role of callous unemotional traits in the diagnosis of conduct disorder. Journal of Child Psychology and Psychiatry 51, 688-695. http://dx.doi.org/10.1111/j. 1469-7610.2009.02199.x.

Rutter, M., 2012. Psychopathy in childhood: Is it a meaningful diagnosis?. British Journal of Psychiatry 200, 175-176. http://dx.doi.org/10.1192/bjp.bp.111.092072

Sevecke, K., Kosson, D., 2010. Relationships of child and adolescent psychopathy to other forms of psychopathology. In: Salekin, R., Lynam, D. (Eds.), Handbook of child and adolescent psychopathy. Guilford Press, New York, NY, pp. 284-314.

Simões, M., 1994. Investigação no âmbito da aferição nacional ao teste das Matrizes Progressivas Coloridas de raven [Research regarding the national validation of Raven's Coloured Progressive Matrices Test] (Unpublished doctoral dissertation) Faculdade de Psicologia e Ciências da Educação da Universidade de Coimbra, Coimbra, Portugal.

Waller, R., Wright, A., Shaw, D., Gardner, F., Dishion, T., Wilson, M., Hyde, L., 2015. Factor structure and construct validity of the parent-reported Inventory of Callous-Unemotional Traits among high-risk 9-year-olds. Assessment 22, 561-580. http://dx.doi.org/10.1177/1073191114556101.

Wasserman, G., McReynolds, L.S., Ko, S., Katz, L., Carpenter, J., 2005. Gender differences in psychiatric disorders at juvenile probation intake. American Journal of Public Health 95, 131-137. http://dx.doi.org/10.2105/AJPH.2003.024737.

West, S., Taylor, A., Wu, W., 2012. Model fit and model selection in structural equation modeling. In: Hoyle, R. (Ed.), Handbook of structural equation modeling. The Guilford Press, New York, pp. 209-231. 